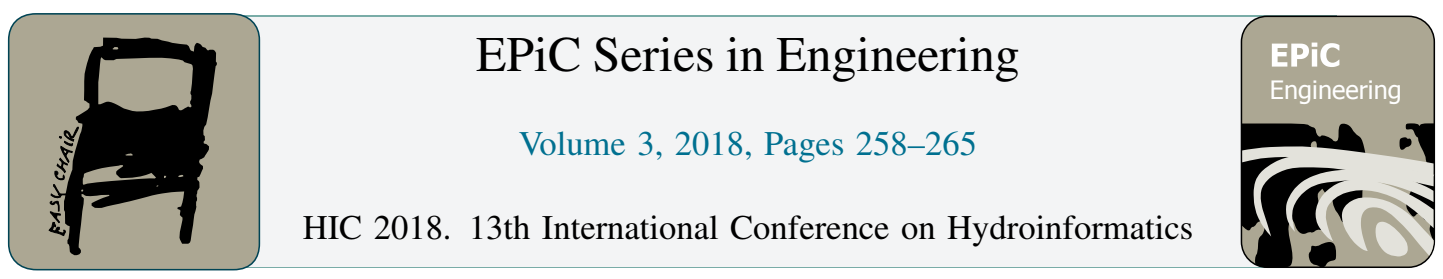

\title{
Dynamic Flood Inundation Forecast for the City of Kulmbach Using Offline Two- Dimensional Hydrodynamic Models
}

\author{
Punit Bhola ${ }^{1 *}$, Jorge Leandro ${ }^{1}$, Iris Konnerth ${ }^{1}$, Kanwal Amin $^{1}$, and Markus Disse ${ }^{1}$ \\ Chair of Hydrology and River Basin Management, Technical University of Munich, Arcisstrasse 21, 80333 \\ Munich, Germany \\ punit.bhola@tum.de
}

\begin{abstract}
The paper presents a new methodology for hydrodynamic-based flood forecast focusing on scenario generation and database queries to select the appropriate flood inundation map in real-time. In operational flood forecasting, discharges are forecast at specific gauges using hydrological models. The water levels are obtained from a rating curve designed for each respective gauge. Particularly for higher discharges when the flow over-spills the side banks, these curves are highly uncertain. Hydrodynamic models are then required to produce realistic inundation maps and water levels. Hydrodynamic models are computationally expensive and therefore not feasible for real-time forecasting. Alternatively, pre-calculated inundation maps can be stored in a database which contains a substantial number of scenarios, and used for extracting the most likely map in real-time. This study investigates the application of offline inundation forecast in the city Kulmbach in Germany.
\end{abstract}

\section{Introduction}

Flood inundation models are central components in any flood risk analysis as they transform the bulk discharge outputs from flood-frequency analyses or rainfall-runoff models into distributed predictions of flood hazards in terms of water depth, inundation extent and flow velocity [1]. Flood forecasting models have the potential to extend the lead time provided to issuing flood warnings and can produce additional information to improve decision- making [2]. The paper presents part of the outcome of the research project FloodEvac funded by the German Federal Ministry of Education and Research (BMBF, FKZ 13N13196).

\section{Study Area and Data}

The river catchment of the Upper Main is in the North-East of the Free State of Bavaria in Southern Germany. The case study is located in the city of Kulmbach (Figure 1). The city has around 26,000

*Corresponding author: punit.bhola@tum.de

G. La Loggia, G. Freni, V. Puleo and M. De Marchis (eds.), HIC 2018 (EPiC Series in Engineering, vol. 3), pp. 258-265 


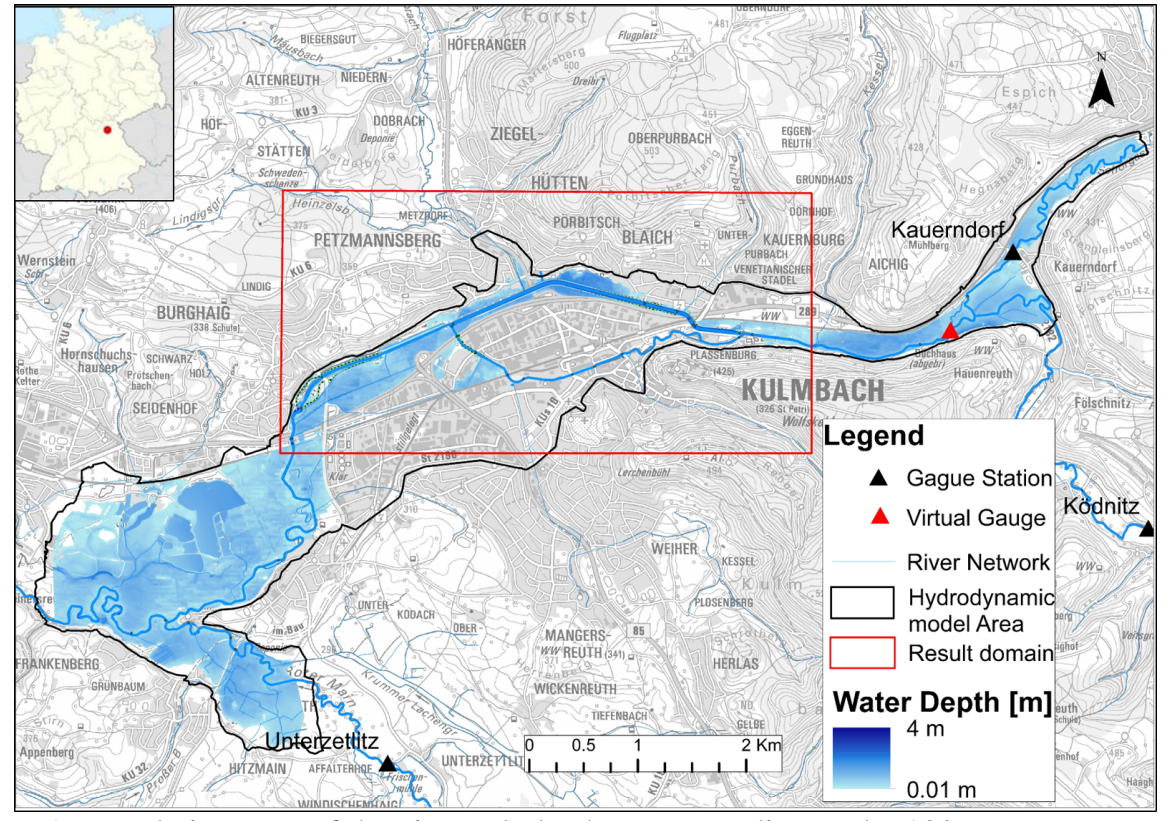

Figure 1. Inundation map of the city Kulmbach corresponding to the 100-year return period.

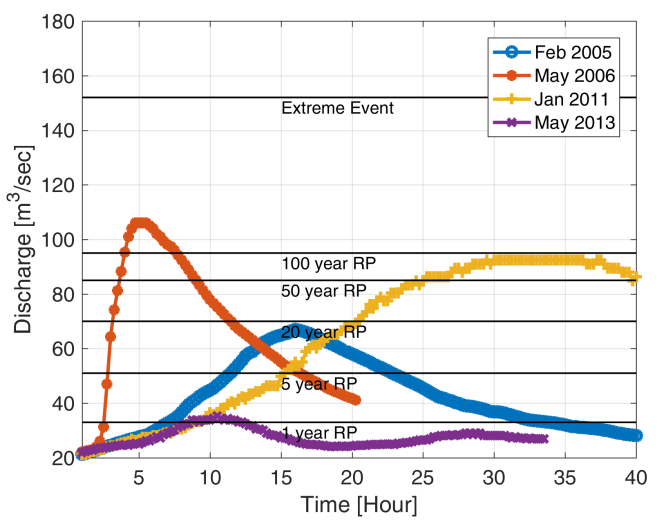

(a) Kauerndorf

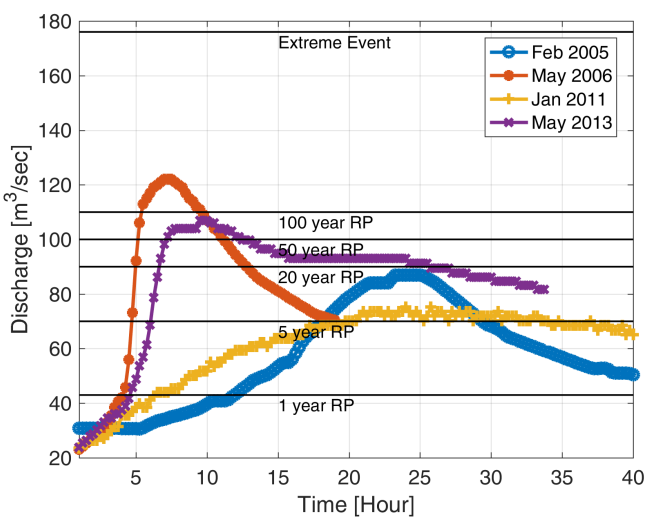

(b) Ködnitz

Figure 2. River discharge data of the gauges (a) Kauerndorf and (b) Ködnitz (source: Hochwassernachrichtendienst Bayern).

inhabitants with a population density of 280 inhabitants per $\mathrm{km}^{2}$, an area of $92.8 \mathrm{~km}^{2}$ and is categorised as a great district city [3]. Traditionally, it has been a manufacturing base for the food and beverage industry. On $28^{\text {th }}$ May 2006, intense rainfall up to 80 litre $/ \mathrm{m}^{2}$ occurred, and within a few hours all the streams and rivers were filled [4]. The incident prompted decision makers to revisit the flood protection measures for the city. Since then, authorities have invested in renewing old regulating structures and flood forecast plans.

Data to build-up the model was collected mainly from the Bavarian Water Authorities (LfU) and 


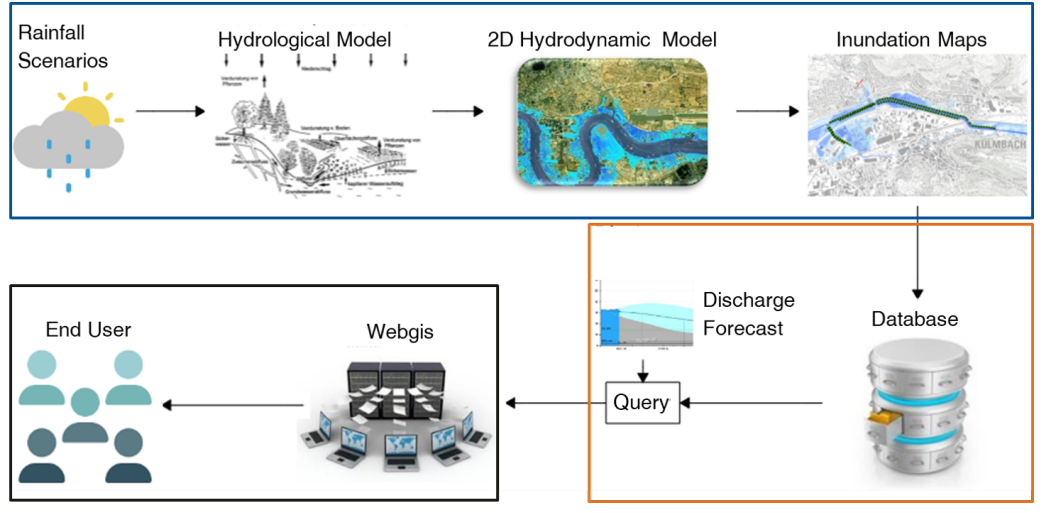

(a)

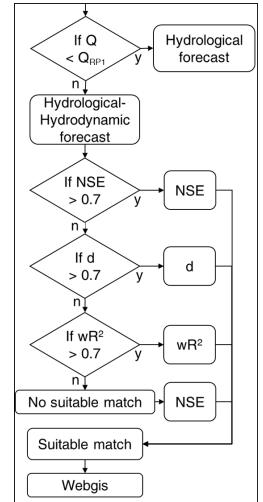

(b)

Figure 3. Model concept, (a) two-dimensional offline flood inundation forecast concept, (b) if-then query.

via field survey. Figure $2 \mathrm{a}$ and $2 \mathrm{~b}$ shows the return period discharges at two gauges upstream of the city, Kaurendorf and Ködnitz respectively. It also shows maximum discharge measured on four extreme events in history. The events have seasonal characteristics based on winter and summer. The two events that occurred in winter (Feb 2005 and Jan 2011) had low peaks but longer duration, whereas the summer events (May 2006 and May 2013) had higher peaks and shorter duration. In May 2013 only the gauge Ködnitz was flooded. The hydrodynamic model was calibrated on the winter event in Jan 2011. The four events were used to validate the offline forecast.

\section{Methodology}

Figure 3a shows the forecast approach, which is divided in three different parts: flood chain modelling, database generation and post processor. The FloodEvac tool was developed in MATLAB to automatize the modelling chain [8]. In the first part, the genesis of flood formation (rainfall generation-hydrological model-hydrodynamic model) was modelled and calibrated for the study area. Inundation maps were produced using synthetically generated rainfall scenarios. Information on the probability of rainfall events was available from KOSTRA (Koordinierte Starkniederschlags-RegionalisierungsAuswertungen) Atlas distributed by the German Meteorological Services (DWD). KOSTRA represents a collection of maps implemented as an interactive computer program. It provides rainfall intensities for different annual probabilities and duration. It was primarily developed for the design of water management systems, such as urban drainage infrastructure or flood retention basins [5]. Rainfall scenarios were generated using various rainfall intensities, duration and distributions. The intensities were varied between 50 and 1000 years return period, ranging from 180 to 1440 minutes duration. Precipitation heights were extrapolated using PEN (Praxisrelevante Extremwerte des Niederschlagsmethod) for higher return period [9]. To produce the rainfall timeseries, rainfall intensities and duration were used in combination with three different types of rainfall distributions: normal stressed, middle stressed and end stressed distributions [10].

The water balance model LARSIM (Large Area Runoff Simulation Model) was used to study the hydrology of the model area and to generate the inflow boundary conditions for the hydrodynamic model. It is operationally used in the flood forecasting centre for the river Main at the Bavarian Environment Agency [6]. The rainfall scenarios were subsequently used as input in the LARSIM model, and the 
results were analysed. Discharges that lie between the one-year return period and the extreme event (Figure 2) were further used as the input boundary conditions for the hydrodynamic model HEC-RAS 2D. The model employs an implicit finite difference solution algorithm to discretize time derivatives and hybrid approximations, combining finite differences and finite volumes to discretize spatial derivatives. The implicit method allows for larger computational time steps compared to an explicit method. HEC-RAS solves 2D Saint Venant equations or the 2D diffusion wave equations [7]. The latter allows for a faster calculation and has greater stability properties due to the less complex numerical schemes. The hydrodynamic model was calibrated on the winter flood event of Jan 2011. Intense rainfall and snow melting in the Fichtel mountains caused floods in several rivers of Upper Franconia. The model domain was categorised in five major land use classes, and roughness parameters were calibrated using 1000 simulations [11]. Figure 1 shows the inundated map produced using the calibrated model for the discharge corresponding to the 100 -year return period.

In the second part, the rainfall scenarios obtained were run with the FloodEvac tool and the 2D hydrodynamic model results were stored in an SQL databank. The generated maps contain spatial and temporal information of water depth and velocity in the study area. To extract the right map from the database, an algorithm was developed (Figure 3b) which identifies similarities between the current flood forecast and the pre-calculated flood maps. In real-time, forecast discharge for the upstream gauges, which can be obtained from LARSIM model, are compared to the database. Coupled hydrologicalhydrodynamic forecast will be active once the forecast discharge reaches the one-year return period. Three measures of fit were identified: Nash-Sutcliffe efficiency (NSE), index of agreement (d) and weighted coefficient of determination $\left(w R^{2}\right)$ [12]. The query follows a sequential if-then order and finds the suitable map from the database for each time step and sends it to the webgis server.

The webgis server forms the third component of the forecast concept: Here, the prepared maps are

made available to the end user. Typical end users are disaster relief organisations such as the Federal Agency for Technical Relief (THW), the German Red Cross and the Bavarian Water Authorities.

\section{Results \& Discussion}

The proposed methodology was validating on four extreme historical hydrological events. Flood inundation maps resulting from the hydrological events as the input boundary conditions (online) were compared to the suitable map selected from the database (offline). The forecast duration is set for 12 hours and the inundation maps are updated at every 3-hour interval. The objective function resulted for the event at every 3-hour interval for the four events are summarised in Table 1. It finds a suitable map for each event and normally chooses NSE or d, with a minimum NSE of 0.86 at $3^{\text {rd }}$ hour in May 2006 and minimum $d$ of 0.76 at $9^{\text {th }}$ hour in Jan 2011. Figure 4 presents the discharge hydrographs resulted from the rainfall scenario at the virtual gauge and the suitable 12-hour forecast window with 3 -hour interval of the four events. Table 2 and 4 gives the relative difference of more than $0.10 \mathrm{~m}$ and Table 3 and 5 more than $0.50 \mathrm{~m}$ between offline and online flooded cells in the selected result domain (Figure 1). Flooded cells are defined as the number of cells containing the water depth more than 0.10 $\mathrm{m}$ [13]. Figure $5-8$ shows the absolute difference between offline and online water depths and the offline inundation maps. The results are further discussed in the following sections.

\subsection{Winter Hydrological Events}

The hydrological event occurred in winter shows similar characteristics such as longer duration and relatively flatter peaks (Figure 4a and 4c). Relative difference table (2 and 3) suggests a slight underprediction of the water depth at the beginning of the forecast and as the time increases over-predicting of water depths. In Feb 2005, the over-predicting was mostly in the range of $0.10 \mathrm{~m}-0.50 \mathrm{~m}$ showing a 


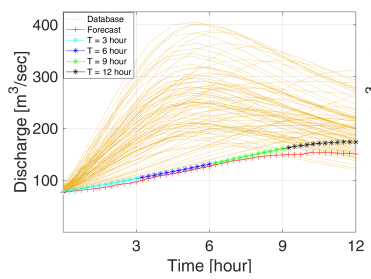

(a) Feb 2005

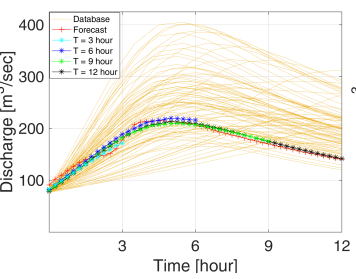

(b) May 2006

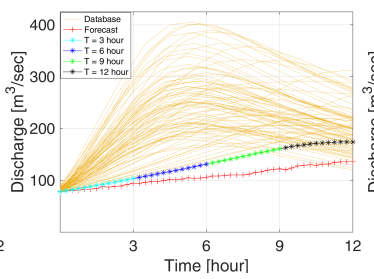

(c) Jan 2011

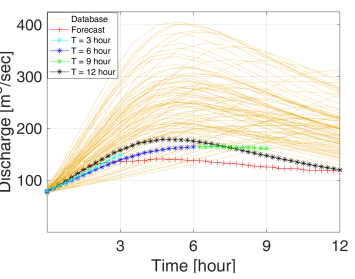

(d) May 2013

Figure 4. Comparison of the discharge hydrographs at the virtual gauge

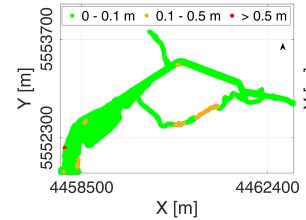

(a) $\mathrm{T}=3$ hour

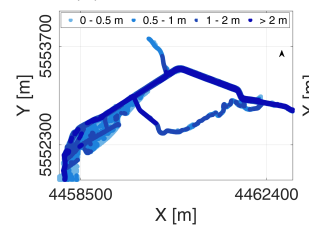

(e) $\mathrm{T}=3$ hour

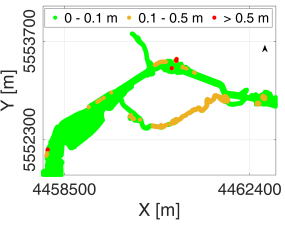

(b) $\mathrm{T}=6$ hour

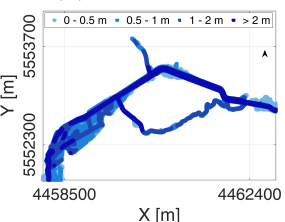

(f) $\mathrm{T}=6$ hour

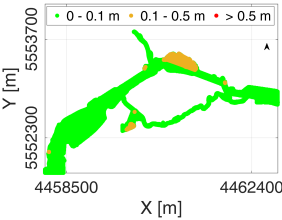

(c) $\mathrm{T}=9$ hour

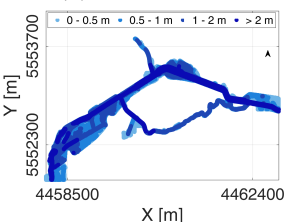

(g) $\mathrm{T}=9$ hour

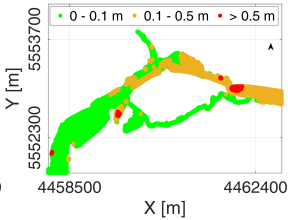

(d) $\mathrm{T}=12$ hour

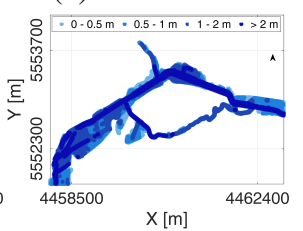

(h) $\mathrm{T}=12$ hour

Figure 5. Absolute error between offline and online water depths and offline flood inundation maps for

Feb 2005

good agreement between offline and online. It can further be seen in Figure 5, the absolute difference in the initial hours is well within the limits of $0.10 \mathrm{~m}$ (green) and at the $12^{\text {th }}$ hour $28 \%$ flooded cells contains a difference in water depth of more than $0.10 \mathrm{~m}$. However, in Jan 2011, the relative difference was reasonably high. Figure 7 shows the increasing error with time, at the $12^{\text {th }}$ hour $80 \%$ cells are overpredicting the water depths by $0.10 \mathrm{~m}$ and out of these $10.7 \%$ are above $0.50 \mathrm{~m}$. The high over-predicting can be caused by the limitation in the current database. The database is currently under improvement to include scenarios covering longer duration.

\subsection{Summer Hydrological Event}

As opposed to the winter, the hydrological events that occurred in summer (May 2006 and May 2013) reaches the peak discharge faster (Figure 4b and 4d). May 2006 was the extreme hydrological event,

Table 1. Objective function of the events at the virtual gauge

\begin{tabular}{lcccc}
\hline Duration & Feb 2005 & May 2006 & Jan 2011 & May 2013 \\
\hline $\mathrm{T}=3$ hour & $0.91(\mathrm{~d})$ & $0.86(\mathrm{NSE})$ & $0.82(\mathrm{~d})$ & $0.92(\mathrm{NSE})$ \\
$\mathrm{T}=6$ hour & $0.92(\mathrm{NSE})$ & $0.95(\mathrm{NSE})$ & $0.78(\mathrm{~d})$ & $0.91(\mathrm{~d})$ \\
$\mathrm{T}=9$ hour & $0.95(\mathrm{NSE})$ & $0.95(\mathrm{NSE})$ & $0.76(\mathrm{~d})$ & $0.81(\mathrm{~d})$ \\
$\mathrm{T}=12$ hour & $0.85(\mathrm{NSE})$ & $0.95(\mathrm{NSE})$ & $0.78(\mathrm{~d})$ & $0.78(\mathrm{~d})$ \\
\hline
\end{tabular}


Table 2. Relative difference between offline and online flooded cells in the selected result domain of the winter events

\begin{tabular}{lcccc}
\hline & \multicolumn{2}{c}{ Feb 2005 [\%] } & \multicolumn{2}{c}{ Jan 2011 [\%] } \\
Duration & $<-0.10 \mathrm{~m}$ & $>0.10 \mathrm{~m}$ & $<-0.10 \mathrm{~m}$ & $>0.10 \mathrm{~m}$ \\
\hline $\mathrm{T}=3$ hour & 1.6 & 0.0 & 7.1 & 0.0 \\
$\mathrm{~T}=$ 6 hour & 4.6 & 0.9 & 2.2 & 25.0 \\
$\mathrm{~T}=$ 9 hour & 0.5 & 6.4 & 0.0 & 31.8 \\
$\mathrm{~T}=12$ hour & 0.0 & 28.0 & 0.0 & 80.0 \\
\hline
\end{tabular}

Table 3. Relative difference between offline and online flooded cells in the selected result domain of the winter events

\begin{tabular}{lcccc}
\hline & \multicolumn{2}{c}{ Feb 2005 [\%] } & \multicolumn{2}{c}{ Jan 2011 [\%] } \\
Duration & $<-0.50 \mathrm{~m}$ & $>0.50 \mathrm{~m}$ & $<-0.50 \mathrm{~m}$ & $>0.50 \mathrm{~m}$ \\
\hline $\mathrm{T}=3$ hour & 0.0 & 0.0 & 0.0 & 0.0 \\
$\mathrm{~T}=$ 6 hour & 0.0 & 0.0 & 0.0 & 1.0 \\
$\mathrm{~T}=9$ hour & 0.0 & 0.0 & 0.0 & 11.9 \\
$\mathrm{~T}=12$ hour & 0.0 & 1.2 & 0.0 & 10.7 \\
\hline
\end{tabular}

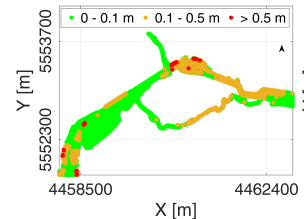

(a) $\mathrm{T}=3$ hour

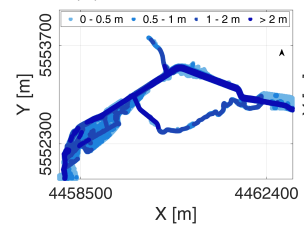

(e) $\mathrm{T}=3$ hour

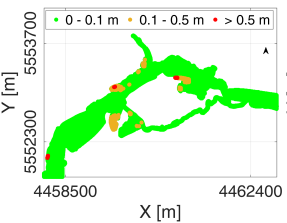

(b) $\mathrm{T}=6$ hour

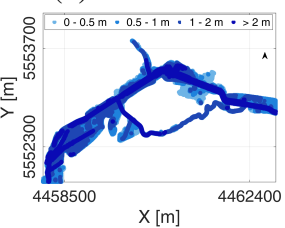

(f) $\mathrm{T}=6$ hour

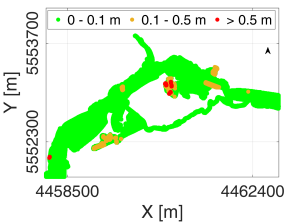

(c) $\mathrm{T}=9$ hour

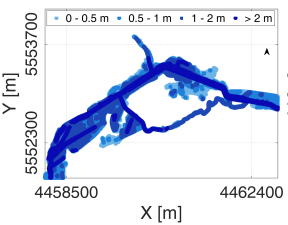

(g) $\mathrm{T}=9$ hour

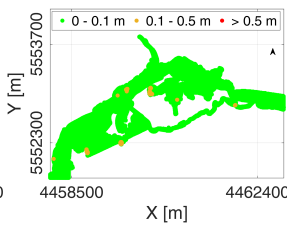

(d) $\mathrm{T}=12$ hour

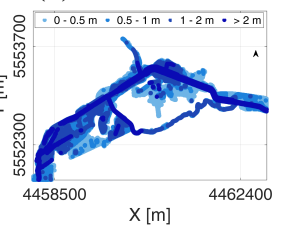

(h) $\mathrm{T}=12$ hour

Figure 6. Absolute error between offline and online water depths and offline flood inundation maps for May 2006

with both the upstream gauges reached a discharge corresponding to the 100-year return period (Figure 3). Table 4 and 5 suggest slight under-prediction at start the $3^{\text {rd }}$ hour in the range of $0.10-0.50 \mathrm{~m}$. As the time increases a good agreement is reached between offline and online, which can also be seen in the Figure 6. Almost all the cells are within the limit of $0.10 \mathrm{~m}$. The protection structures are breached and critical infrastructure and industrial areas are flooded (Figure 6). In May 2013, however only one of the gauge was flooded therefore the discharge was considerably low at the virtual gauge. The results show a good agreement at the early hours but as the time increases the difference increases between offline and online water depths. Furthermore, Figure 8 shows the flood was mainly retained in the floodplain and only affected part of the city. 
Table 4. Relative difference between offline and online flooded cells in the selected result domain of the summer events

\begin{tabular}{lcccc}
\hline & \multicolumn{2}{c}{ May 2006 [\%] } & \multicolumn{2}{c}{ May 2013 [\%] } \\
Duration & $<-0.10 \mathrm{~m}$ & $>0.10 \mathrm{~m}$ & $<-0.10 \mathrm{~m}$ & $>0.10 \mathrm{~m}$ \\
\hline $\mathrm{T}=3$ hour & 20.4 & 2.2 & 61.1 & 0.0 \\
$\mathrm{~T}=$ 6 hour & 2.5 & 0.0 & 1.6 & 35.1 \\
$\mathrm{~T}=9$ hour & 1.9 & 0.5 & 0.0 & 73.6 \\
$\mathrm{~T}=12$ hour & 0.2 & 0.1 & 3.0 & 29.0 \\
\hline
\end{tabular}

Table 5. Relative difference between offline and online flooded cells in the selected result domain of the summer events

\begin{tabular}{lcccc}
\hline & \multicolumn{2}{c}{ May 2006 [\%] } & \multicolumn{2}{c}{ May 2013 [\%] } \\
Duration & $<-0.50 \mathrm{~m}$ & $>0.50 \mathrm{~m}$ & $<-0.50 \mathrm{~m}$ & $>0.50 \mathrm{~m}$ \\
\hline $\mathrm{T}=3$ hour & 0.3 & 0.0 & 1.2 & 0.0 \\
$\mathrm{~T}=6$ hour & 0.1 & 0.0 & 0.0 & 0.0 \\
$\mathrm{~T}=$ 9 hour & 0.1 & 0.0 & 0.0 & 3.2 \\
$\mathrm{~T}=12$ hour & 0.0 & 0.0 & 0.0 & 5.2 \\
\hline
\end{tabular}

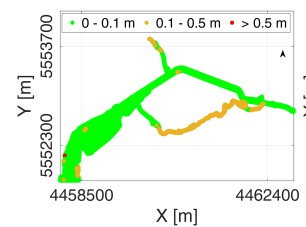

(a) $\mathrm{T}=3$ hour

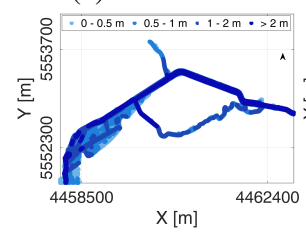

(e) $\mathrm{T}=3$ hour

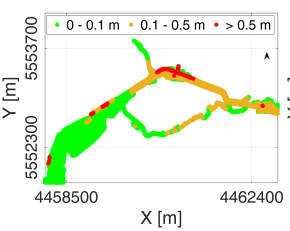

(b) $\mathrm{T}=6$ hour

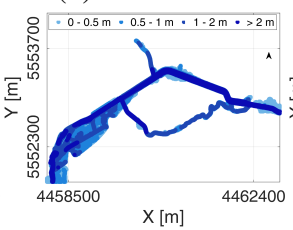

(f) $\mathrm{T}=6$ hour

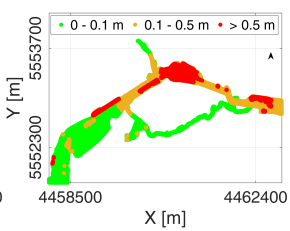

(c) $\mathrm{T}=9$ hour

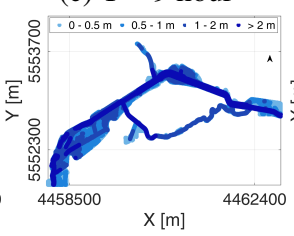

(g) $\mathrm{T}=9$ hour

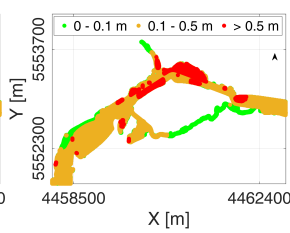

(d) $\mathrm{T}=12$ hour

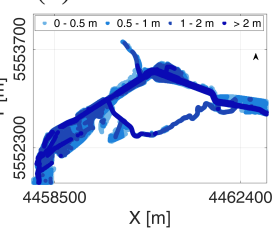

(h) $\mathrm{T}=12$ hour

Figure 7. Absolute error between offline and online water depths and offline flood inundation maps for Jan 2011

\section{Conclusions}

To overcome the inability to use hydrodynamic flood forecast due to its high computational time, a framework of an offline flood forecast is presented and validation for four extreme historical hydrological events. The validation gave satisfactory comparison between offline and online flood inundation maps for the summer and winter season. It was observed that the difference between the offline and online water depths increases with the forecast time. The under-prediction of the water depth in the initial hour and over-prediction in later stages was observed in all the four cases. The extreme event in May 2006 shown the best match between online and offline and it can be concluded that the methodology worked for high and short duration peaks. However, in Jan 2011 and May 2013, the water depths were 


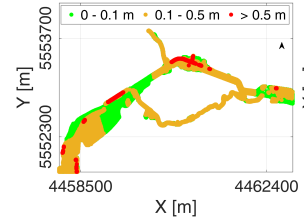

(a) $\mathrm{T}=3$ hour

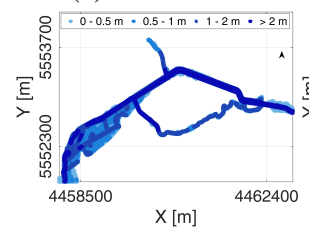

(e) $\mathrm{T}=3$ hour

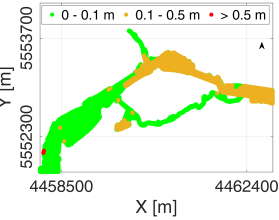

(b) $\mathrm{T}=6$ hour

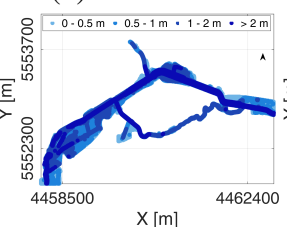

(f) $\mathrm{T}=6$ hour

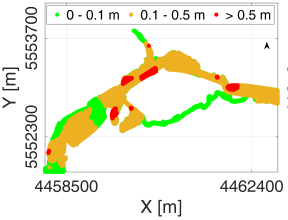

(c) $\mathrm{T}=9$ hour

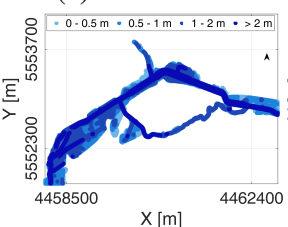

(g) $\mathrm{T}=9$ hour

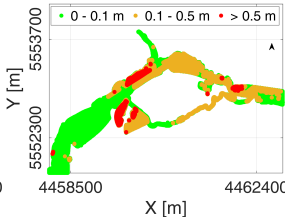

(d) $\mathrm{T}=12$ hour

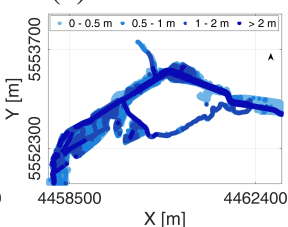

(h) $\mathrm{T}=12$ hour

Figure 8. Absolute error between offline and online water depths and offline flood inundation maps for May 2013

over-predicted. To accurately forecast, it is important to include more rainfall scenarios which cover longer duration discharge hydrographs. As mentioned, future work will see more rainfall scenarios being generated and added to the database in order to strengthen the proposed framework.

\section{References}

[1] K. Beven \& J. Hall, 2014 Applied uncertainty analysis for flood risk management. Imperial College Press.

[2] K. Sene, 2013 Flash Floods: Forecasting and Warning. Springer.

[3] Stadtdaten von Kulmbach, accessed 10 October 2016 retrieved from http://www.kulmbach.de/xist4c/web/Kulmbach-Rathaus-Stadtinfo-Geschichte_id_272_.htm.

[4] TVO/, tvo Fernsehen fuer Oberfranken, accessed 10 October 2016 retrieved from https://www.tvo.de/hochwasserschautz-kulmbach-neugestaltung-der-flutmulde-142915/.

[5] B. Thiebes, 2012 Landslide analysis and early warning systems : local and regional case study in the Swabian Alb. Springer Theses.

[6] K. Ludwig \& M. Bremicker, 2006 The water balance model LARSIM: design, content and applications. Freiburg i. Br., Inst. fur Hydrologie der Univ.

[7] US Army Corps of Engineers, 2016 HEC-RAS river analysis system: 2D modeling user's manual. Davis, CA. Institute for Water Resources, Hydrologic Engineering Center.

[8] J. Leandro, I. Konnerth, P. Bhola, K. Amin, F. Köck \& M. Disse, 2017 FloodEvac Interface zur Hochwassersimulation mit integrierten Unsicherheitsabschätzungen. Tag der Hydrologie, Trier.

[9] H.-R. Verworn \& R. Draschoff, 2008 Turbulent PEN-Erweiterung, Praxisrelevante Extremwerte des Niederschlags (PEN). Leibnitz Universität Hannover.

[10] DWARegelwerk, 2006 Arbeitsblatt DWA-A 118, Hydraulische Bemessung und Nachweis von Entwässerungssystemen. Hennef.

[11] S. Ederle, 2017 A simple raster-based model for floodplain Inundation and uncertainty assessment; Case study: city Kulmbach (Germany). Technische Universität München, 2017.

[12] P. B. Krause, F. Bäse, 2005 Comparison of different efficiency criteria for hydrological model assessment. Advances in Geosciences, 2017. 5, 89-97

[13] Leandro, J., Djordjević, S., Chen, A. S., Savić, D. A., and Stanić, M. 2011 Calibration of a 1D/1D urban flood model using 1D/2D model results in the absence of field data. Journal of Water Science and Technology-IWA, 2011. 64(5), 1016-1024 